\title{
Simulation Study of Adrenaline Synthesis from Phenylalanine
}

Halla T. Mohammed, and Abbas A-Ali Drea

Chemistry Department, College of Science, Babylon University, Hilla, IRAQ

\section{ABSTRACT}

aadreab22@yahoo.com

Simulation study of Adrenaline synthesis from Phenylalanine has been carried out using semi-empirical methods (PM3) and density functional theory (DFT) STO-3G level of theory. Geometrical properties and vibration mods have been calculated for all structures. Different probable products have been suggested for each reaction and the most probable products being selected depending upon the electronic properties to prove the pathway of reactions that's needed to synthesis adrenaline in the human body.

The calculations show the most probable product than other structurs due its energetic values of total energy, energy barrier value, heat of formation, zero point energy, imaginary frequency and rate constant that's equal to $\left(5.554^{*} 10^{12}, 5.572^{*} 10^{12}, 7.857^{*} 10^{12}, 1.331^{*} 10^{13}, 1.116^{*} 10^{13}\right)$ respectively by $\mathrm{s}^{-1}$ units. Thermodynamic functions $(\Delta \mathrm{H}, \Delta \mathrm{S}$, $\Delta G)$ have been calculated for five steps reactions of Adrenaline synthesis . In reaction 1 equal to $\left(-69.468,1.37^{\star} 10^{-4}\right.$, $66.610)$, reaction $2\left(-46.453,3.044^{*} 10^{-3},-64.710\right)$, reaction $3(-63.734,0.022,138.900)$, reaction $4\left(87.036,8.631^{*} 10^{-3}\right.$, $451.510)$ and reaction $5(-6.722,-0.025,346,800)$ respectively by $\mathrm{kCal} / \mathrm{mol}, \mathrm{kCal} / \mathrm{mol} / \mathrm{deg}$, and $\mathrm{kCal} / \mathrm{mol}$ respective units. The chemical reactivity or energy gap has been calculated for the most probable products in the pathway of adrenaline synthesis .

Keywords: Simulation Study; Semi-empirical method; DFT; Adrenaline.

\section{Council for Innovative Research}

Peer Review Research Publishing System

\section{Journal: Journal of Advances in Chemistry}

Vol. 12, No. 1

www.cirjac.com

editorjaconline@gmail.com, editor@cirjac.com 


\section{INTRODUCTION}

Adrenaline (Epinephrine or 4,5- $\beta$-trihydroxy phenethylamine) has formula chemical formula $\mathrm{C}_{6} \mathrm{H}_{13} \mathrm{NO}_{3}$. It,s a hormone and a neurotransmitter secreted by the inner part of the adrenal gland, which produces in the heart of the adrenal in response to physical or mental stress ${ }^{1}$. Adrenaline has one amino group that is associated with an aromatic ring with a two-carbon chain, $-\mathrm{CH}_{2}-\mathrm{CH}_{2}-$ ). Epinephrine classified in the class of compounds called catecholamine which is a monoamine derived from the amino acid tyrosine, and also the same case derived from phenylalanine ${ }^{2}$. Figure 1 shows the chemical structure of Adrenaline.<smiles>CNC[C@H](O)c1ccc(O)c(O)c1</smiles>

Figure 1: Chemical structure of Adrenaline.

Adrenaline was discovered as a substance produced from adrenal gland in 1886 by William Bates reported, than was isolated and recognized in 1895 by Napoleon Cybulski ${ }^{3}$, and synthesized of adrenaline for the first time artificially in 1904 by Friedrich Stolz ${ }^{4}$. Metabolic reactions that occur in Adrenaline synthesis in the human body from Phenylalanine are Oxidation of Phenylalanine to Tyrosine, Oxidation of Tyrosine to L-DOPA, Decarboxylation of L-DOPA to Dopamine, Oxidation of Dopamine to Noradrenaline, And at the last methylation of Noradrenaline to Adrenaline ${ }^{5}$ through the following steps:

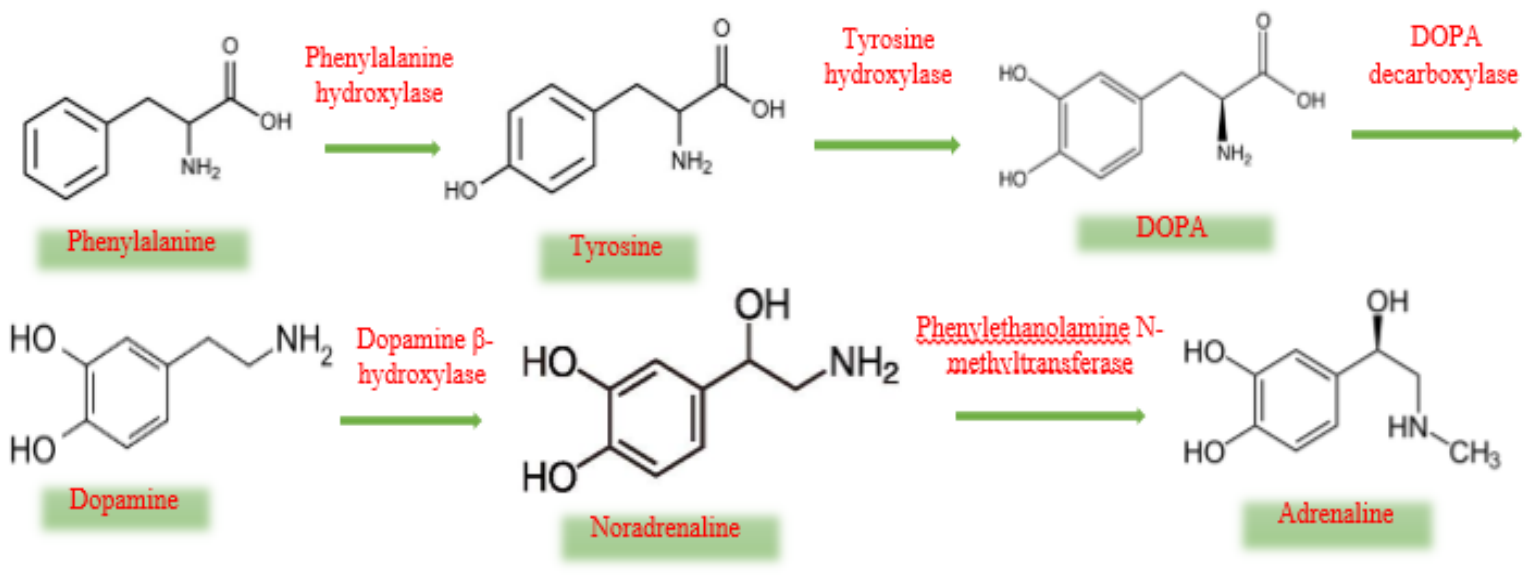

The present study tends to prove the beast's path of Adrenaline synthesis from Phenylalanine theoretically through the quantum calculations treatment of the electronic and geometrical structure by using PM3 of semiempirical calculations and DFT minimal STO-3G. Different probables products will be suggested in each reaction to find the most probable product.

\section{COMPUTATIONAL DETAILS}

Theoretical calculations were completed by using the computational implemented in the Hyperchem Version 8.0.9 program ${ }^{6,7}$. Geometry optimization, electronic energies, heat of formation for all chemical compounds that's needed to Adrenaline synthesis from Phenylalanine have been optimized at semi empirical method and DFT- STO3G. The highest occupied molecular orbital (HOMO) and the lowest unoccupied molecular orbital (LUMO) are studied to calculate the Energy gap $(\Delta \mathrm{E})^{8,9}$. Thermodynamic parameters $(\Delta \mathrm{G}, \Delta \mathrm{H}, \Delta \mathrm{S})$ were calculated at semi-empirical method PM3 level ${ }^{10}$. Table 1 shows the chemical structures and abbreviations of all compounds. 
Table 1: List of chemical structures and abbreviations.

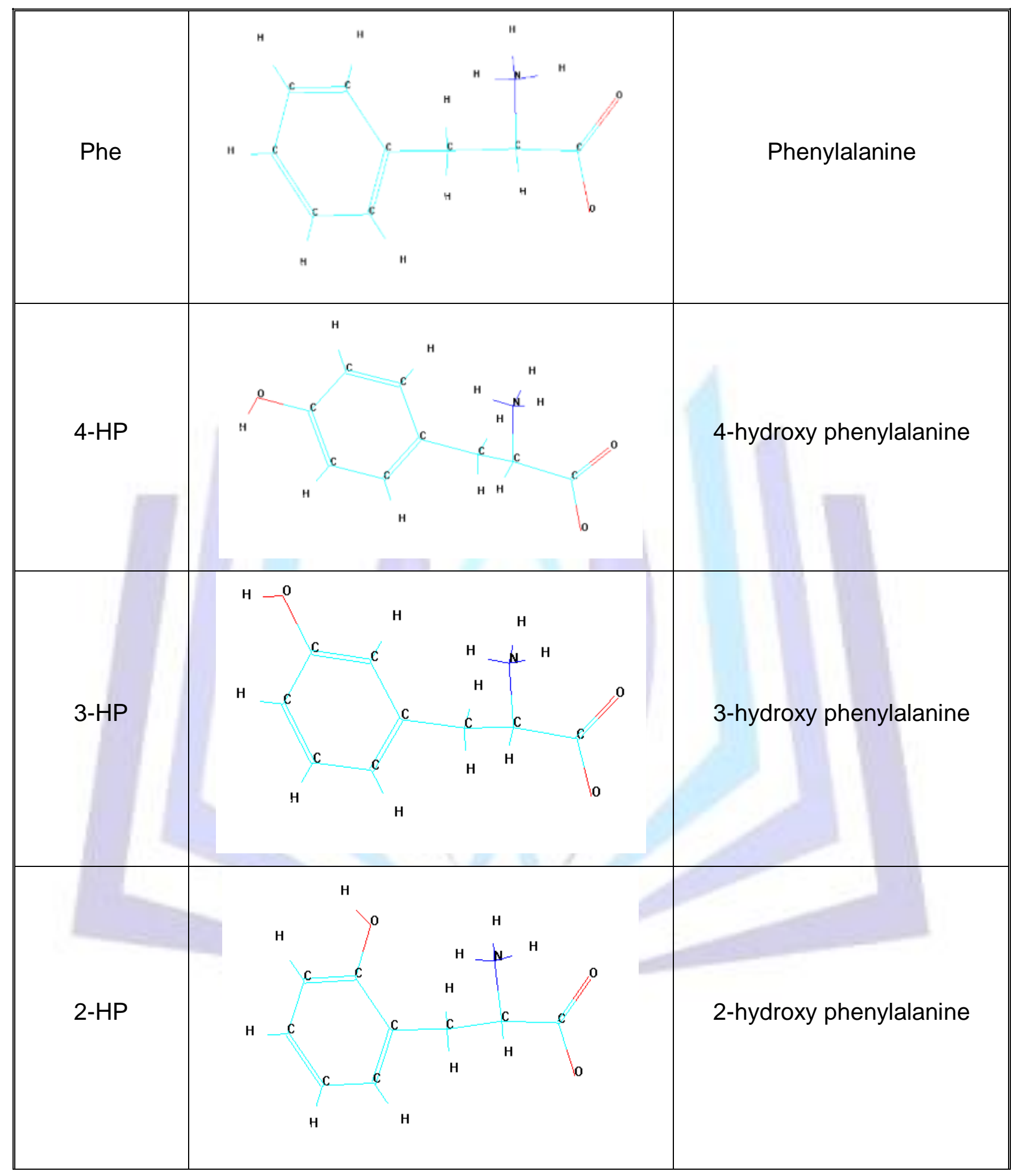


ISSN 2321-807X

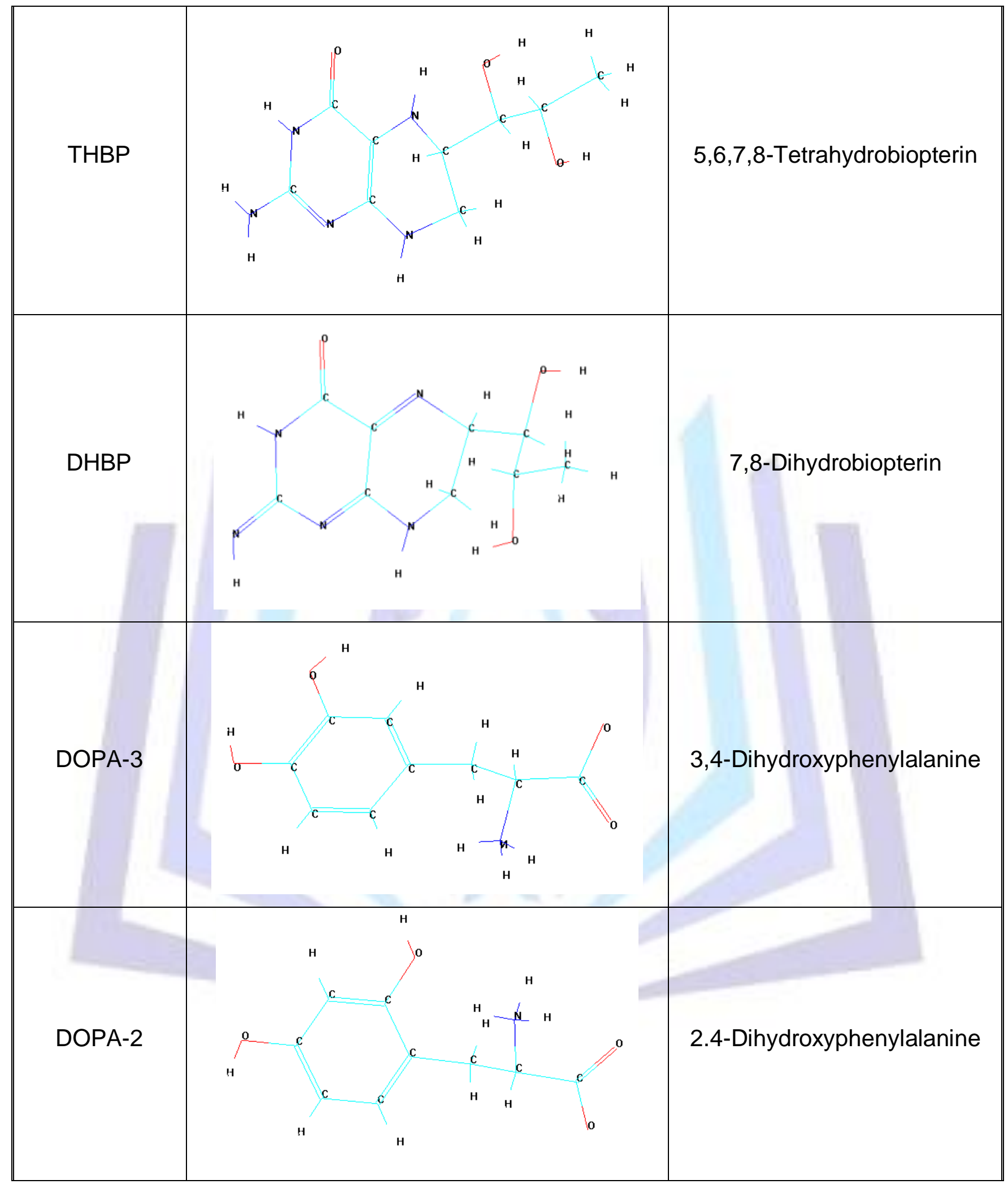


ISSN 2321-807X

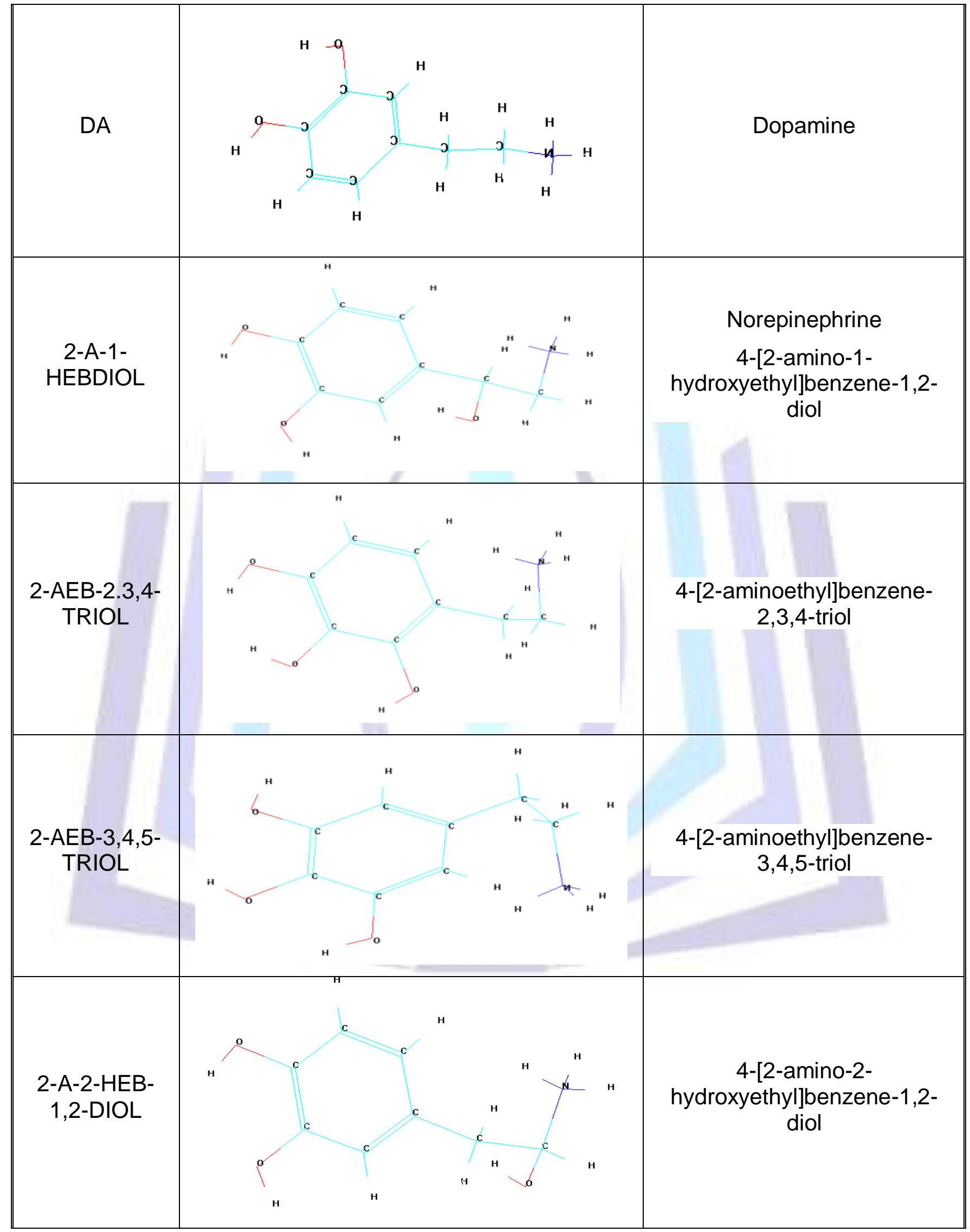


ISSN 2321-807X

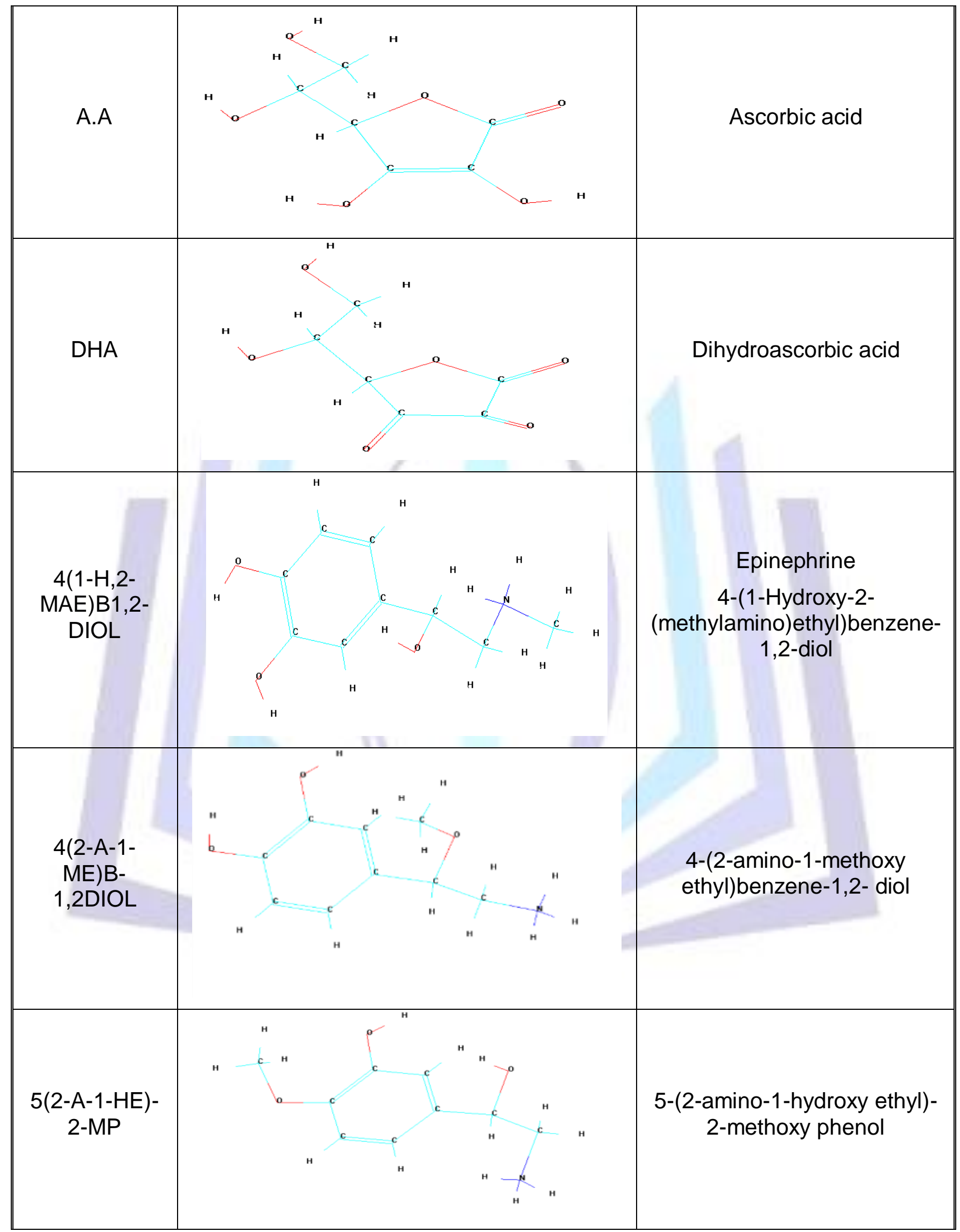




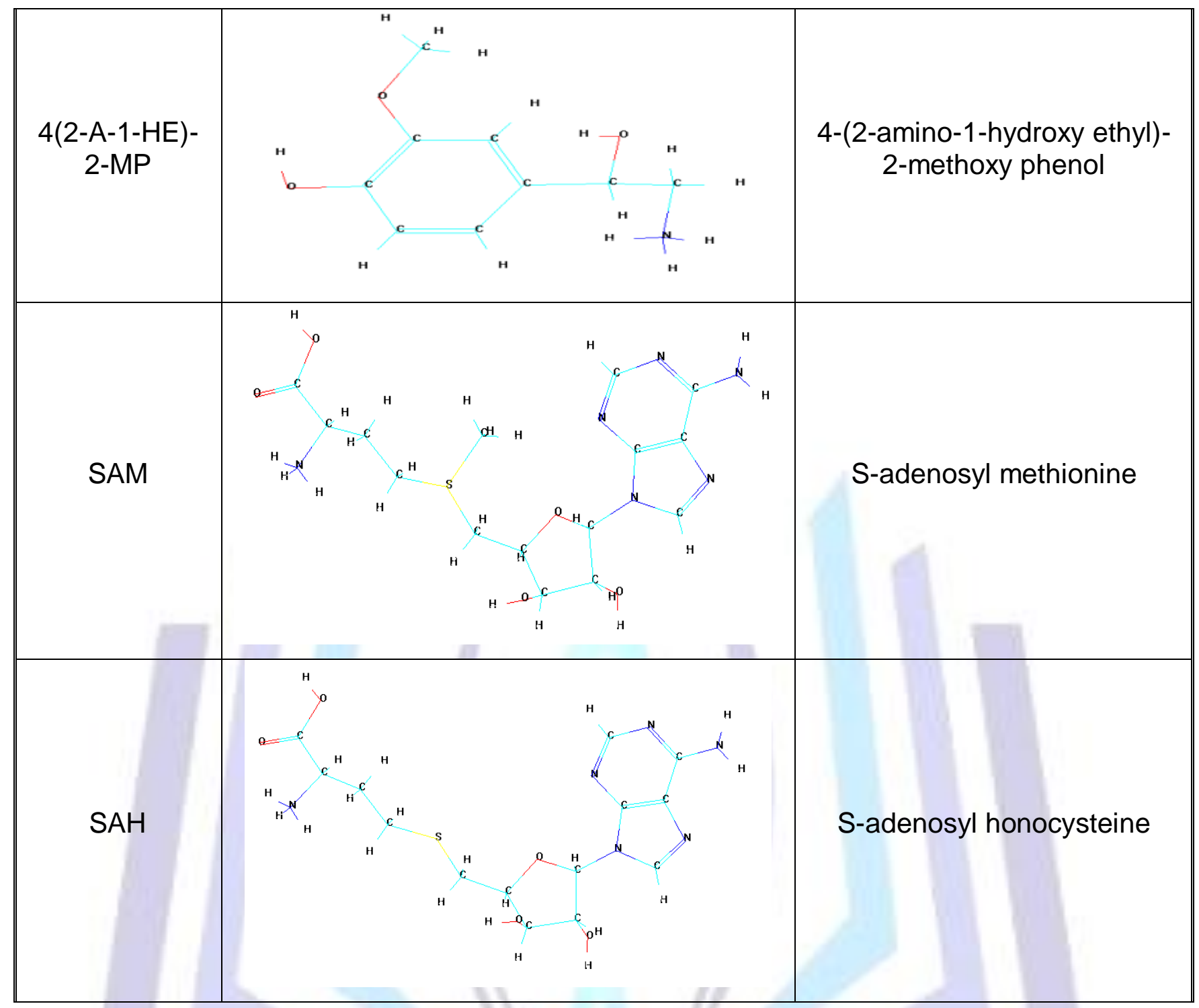

\section{RESULTS AND DISCUSSION}

The study included the adrenaline synthesis from phenylaniline in vacuum taking into account the factors of the reaction at $25^{\circ} \mathrm{C}$ and $1 \mathrm{M}$ concentration for all chemical compounds by different quantum calculation methods. The energetic properties of Adrenaline synthesis were calculated by semi empirical PM3 method and listed in Table 2 . Table 2 show that the rate constant of raction of aquired values is very high, thats mean these ractions are very fast, because the values of the rate constant equal to the speed of the reaction at the concentrations used. These reactions are very fast because they are nerve reactions ${ }^{11}$. In very fast reactions that cannot control the value of the energy barrier which equal to the value of activation energy is negative ${ }^{12}$. Thermodynamic parameters indicate that the reactions 1 and 3 are exothermic and spontaneous, reaction 2 and 5 are exothermic and nonspontaneous while reaction 4 is endothermic and spontaneous according to the concept of thermodynamic ${ }^{13,14}$. 
Table 2: Energetic properties for synthetic reactions of Adrenaline.

\begin{tabular}{|c|c|c|c|c|c|c|c|}
\hline Steps & Reactants & $\begin{array}{l}\text { Probabilities } \\
\text { Products }\end{array}$ & $\begin{array}{c}\text { Energy } \\
\text { barrier } \\
(\mathrm{kCal} / \mathrm{mol})\end{array}$ & $\begin{array}{c}\mathrm{H} \Delta \\
\left(\begin{array}{c}\mathrm{kCal} / \mathrm{mo} \\
\mathrm{l})\end{array}\right.\end{array}$ & $\begin{array}{c}\Delta \mathrm{S} \\
(\mathrm{kCal} / \mathrm{mol} / \mathrm{deg})\end{array}$ & $\begin{array}{c}\Delta \mathrm{G} \\
(\mathrm{kCal} / \mathrm{mol})\end{array}$ & $\begin{array}{c}\mathrm{k} \\
\left(\mathrm{s}^{-1}\right)\end{array}$ \\
\hline \multirow{3}{*}{ 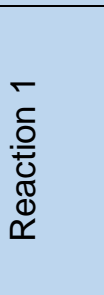 } & \multirow{3}{*}{$\begin{array}{c}\mathrm{O}_{2}+\mathrm{Phe}+ \\
\text { THBP }\end{array}$} & $\begin{array}{c}\mathrm{H}_{2} \mathrm{O}+4-\mathrm{HP}+ \\
\text { DHBP }\end{array}$ & 69.469- & -69.468 & $1.37 * 10^{-4}$ & -66.610 & $5.554 * 10^{12}$ \\
\hline & & $\begin{array}{c}\mathrm{H}_{2} \mathrm{O}+3-\mathrm{HP}+ \\
\text { DHBP }\end{array}$ & -69.561 & -69.560 & $4.63^{*} 10^{-4}$ & -66.810 & $5.552^{*} 10^{12}$ \\
\hline & & $\begin{array}{c}\mathrm{H}_{2} \mathrm{O}+2-\mathrm{HP}+ \\
\text { DHBP }\end{array}$ & $-69,427$ & -69.426 & $-2.428^{*} 10^{-3}$ & -65.810 & $5.561^{*} 10^{12}$ \\
\hline \multirow{2}{*}{ 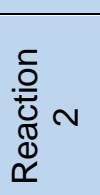 } & \multirow{2}{*}{$\begin{array}{c}\text { 4- } \mathrm{HP}_{+} \mathrm{O}_{2+}+ \\
\mathrm{THBP}\end{array}$} & $\begin{array}{c}\text { DOPA- } 3+\mathrm{H}_{2} \mathrm{O}+ \\
\text { DHBP }\end{array}$ & -17880 & -49.453 & $-3.044^{*} 10^{-3}$ & -64.710 & $5.572 * 10^{12}$ \\
\hline & & $\begin{array}{c}\text { DOPA-2+ } \mathrm{H}_{2} \mathrm{O}+ \\
\text { DHBP }\end{array}$ & -17878.727 & -48.18 & $-2.5791^{*} 10^{-3}$ & -66.110 & $5.558^{*} 10^{12}$ \\
\hline 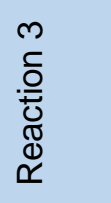 & DOPA-3 & $\mathrm{DA}+\mathrm{CO}_{2}$ & 131.563 & -63 & 0.022 & 138.900 & $7.857^{*} 10^{12}$ \\
\hline \multirow{4}{*}{ 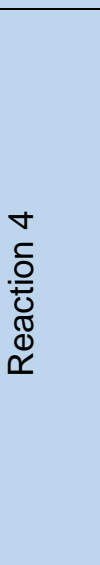 } & \multirow{4}{*}{$\mathrm{DA}+\mathrm{A} \cdot \mathrm{A}+\mathrm{O}_{2}$} & $\begin{array}{c}\text { 2-A-1- } \\
\text { HEBDIOL } \\
+\mathrm{DHA}+\mathrm{H}_{2} \mathrm{O}\end{array}$ & -461.941 & 87.036 & $8.631 * 10^{-3}$ & -451.510 & $1.331 * 10^{13}$ \\
\hline & & $\begin{array}{c}\text { 2-AEB-2.3,4- } \\
\text { TRIOL } \\
+\mathrm{DHA}+\mathrm{H}_{2} \mathrm{O}\end{array}$ & -469.354 & 169.623 & $6.864^{*} 10^{-3}$ & -456.810 & $2.874^{\star} 10^{12}$ \\
\hline & & $\begin{array}{c}\text { 2-AEB-3,4,5- } \\
\text { TRIOL } \\
+ \text { DHA }+\mathrm{H}_{2} \mathrm{O}\end{array}$ & -469.195 & 169.782 & $4.247^{\star} 10^{-3}$ & -456.910 & $2.874^{*} 10^{12}$ \\
\hline & & $\begin{array}{c}\text { 2-A-2-HEB- } \\
\text { 1,2-DIOL } \\
+\mathrm{DHA}+\mathrm{H}_{2} \mathrm{O}\end{array}$ & -469.845 & 169.132 & $6.543^{*} 10^{-3}$ & -457.710 & $2.871 * 10^{12}$ \\
\hline \multirow{4}{*}{ 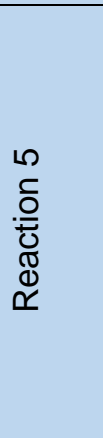 } & \multirow{4}{*}{$\begin{array}{l}\text { 2-A-1- } \\
\text { HEBDIOL+S } \\
\text { AM }\end{array}$} & $\begin{array}{c}4(1-\mathrm{H}, 2- \\
\text { MAE)B1,2- } \\
\text { DIOL +SAH }\end{array}$ & 346.857 & -6.7 & -0.025 & 346.800 & $1.116^{*} 10^{13}$ \\
\hline & & $\begin{array}{l}\text { 4(2-A-1-ME)B- } \\
1,2 \mathrm{DIOL}+\mathrm{SAH}\end{array}$ & 359.71 & 6.131 & -0.026 & 351.900 & $1.125^{*} 10^{13}$ \\
\hline & & $\begin{array}{c}\text { 5(2-A-1-HE)-2- } \\
M P+S A H\end{array}$ & 355.929 & 2.35 & $0.024-$ & 356.800 & $1.135^{\star} 10^{13}$ \\
\hline & & $\begin{array}{c}\text { 4(2-A-1-HE)-2- } \\
\mathrm{MP}+\mathrm{SAH}\end{array}$ & 352.812 & -0.768 & -0.021 & 352.900 & $1.127^{*} 10^{13}$ \\
\hline
\end{tabular}


Scheme 1 show the pathway of Adrenaline synthesis accourding to energetic properties . Scheme 1

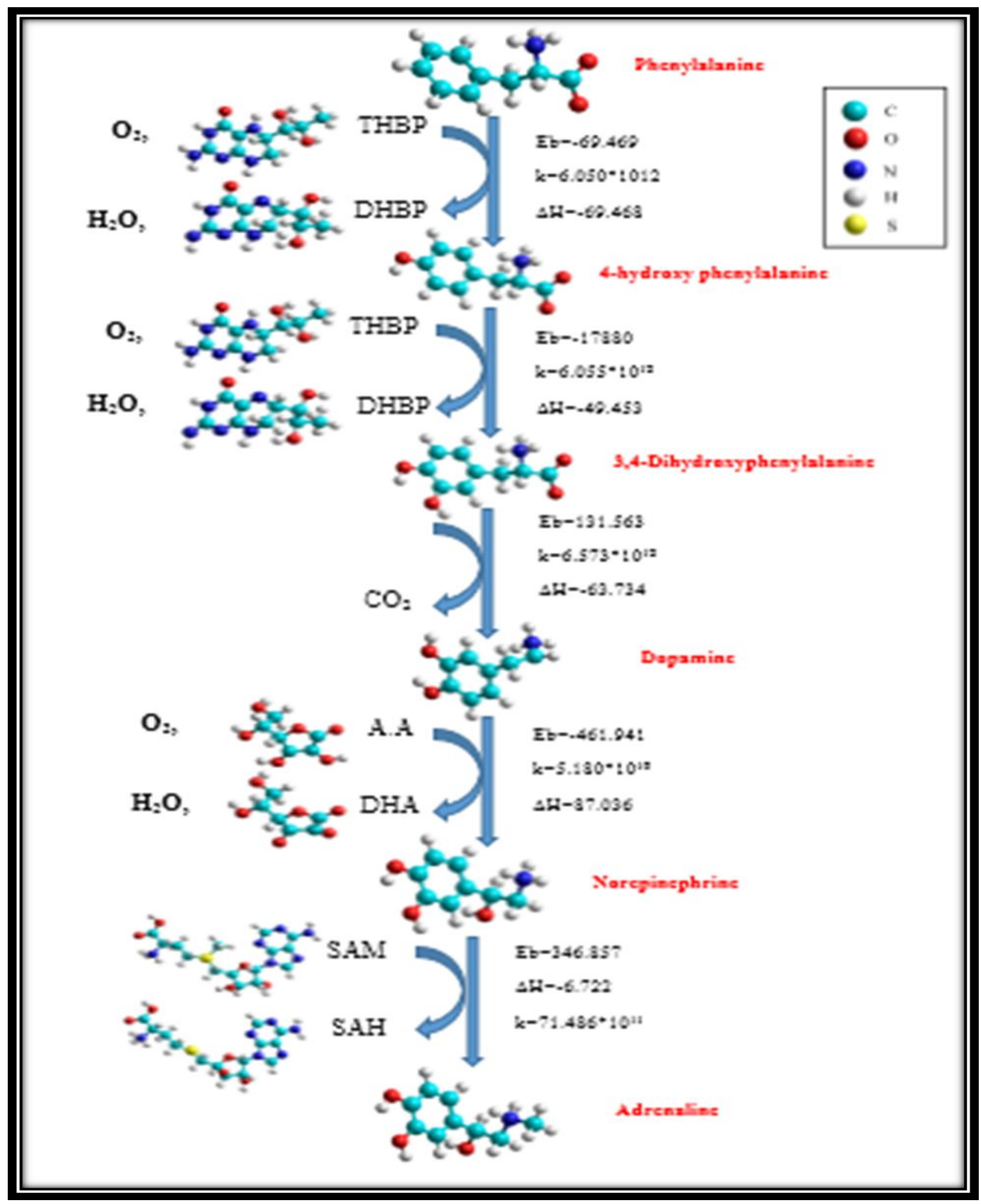

. Pathway of Adrenaline synthesis within sevral steps. 
The energetic properties for all chemical compounds were calculated by the DFT- STO-3G level of theory as show in Table 3.

Table 3: The properties of energy for all chemical compounds.

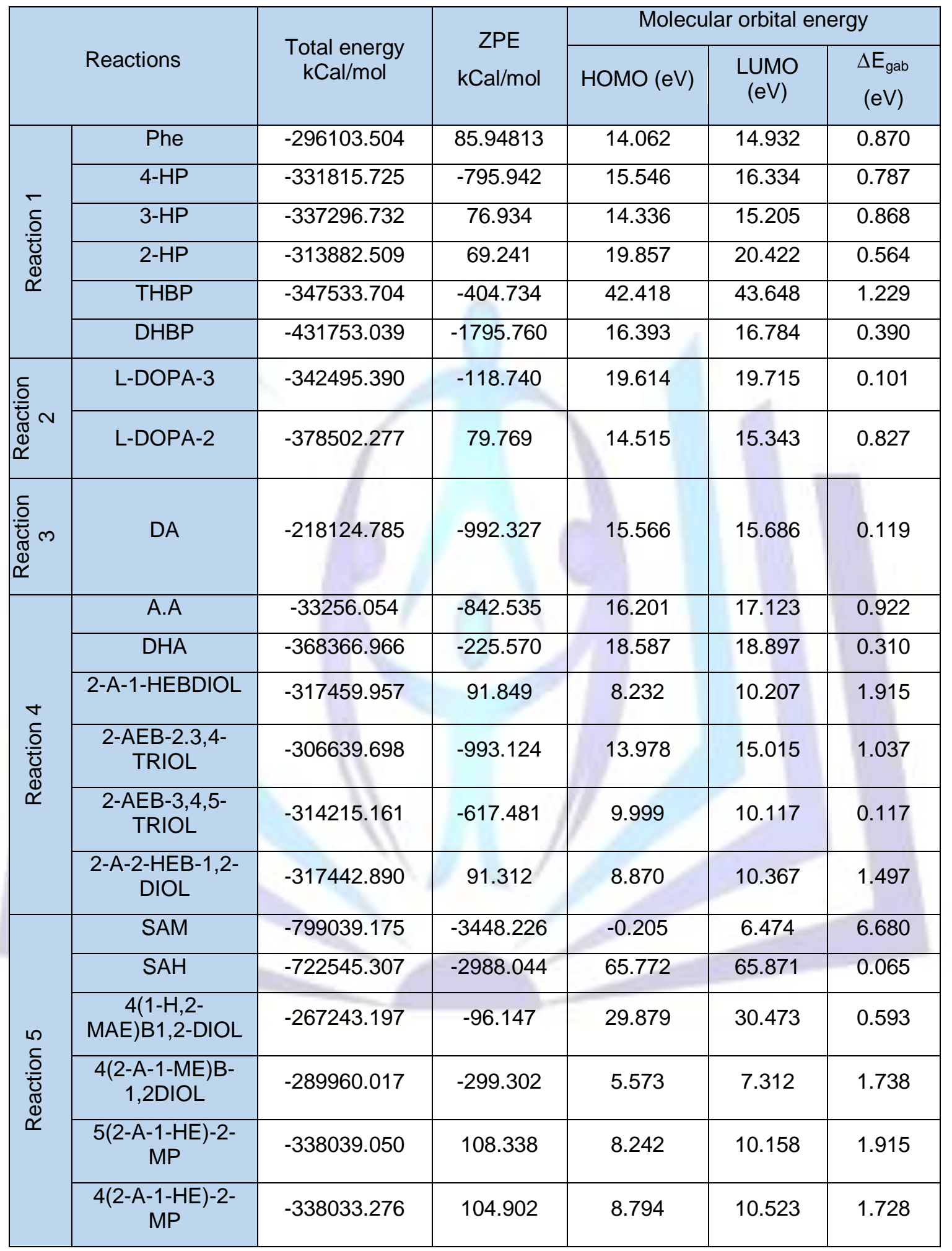

The energy band gap of all compounds through the adrenaline synthesis pathway was calculated ${ }^{15}$ and showed as below: 


\section{Phe \\ $\rightarrow 4-\mathrm{HP}$ \\ L-DOPA-3 \\ DA \\ $(0.870 \mathrm{eV})$ \\ $(0.787 \mathrm{eV})$ \\ $(0.101 \mathrm{eV})$ \\ $(0.119 \mathrm{eV})$ \\ 2-A-1-HEBDIOL 4(1-H, 2-MAE)B1,2-DIOL}

\section{$(1.915 \mathrm{eV})$}

$(0.593 \mathrm{eV})$

The energy gap value for all chemical compounds in the pathway of Adrenaline synthesis indicates they are good conductors ${ }^{16}$, this enables to transfer electrical signals in the nervous system. The HOMO and LUMO orbitals were calculated by the DFT- STO-3G level of theory, they showed in Table 3.

Table 3: The molecular properties of chemical meoties calculated by the DFT- STO-3G level of theory.

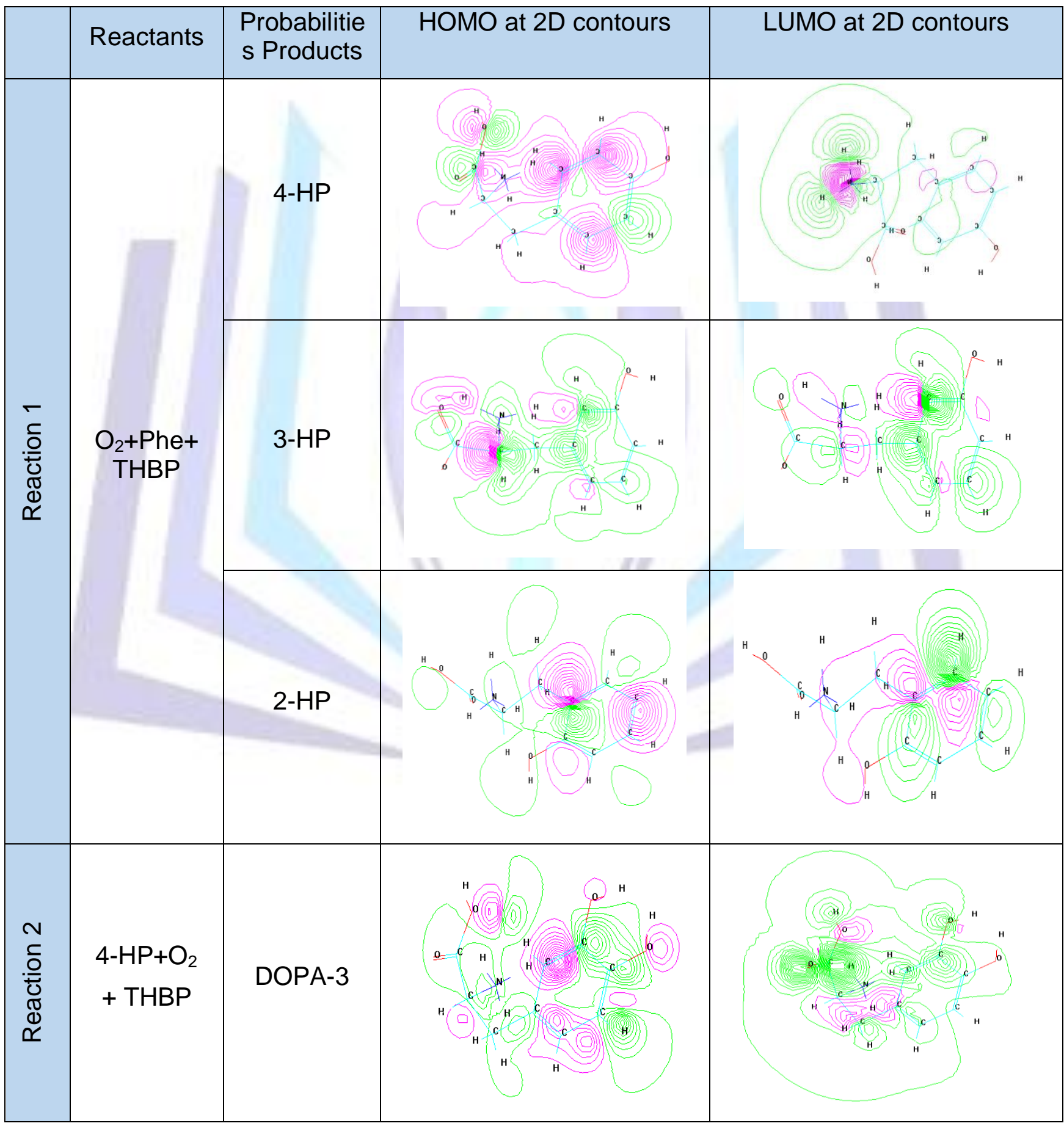


ISSN 2321-807X

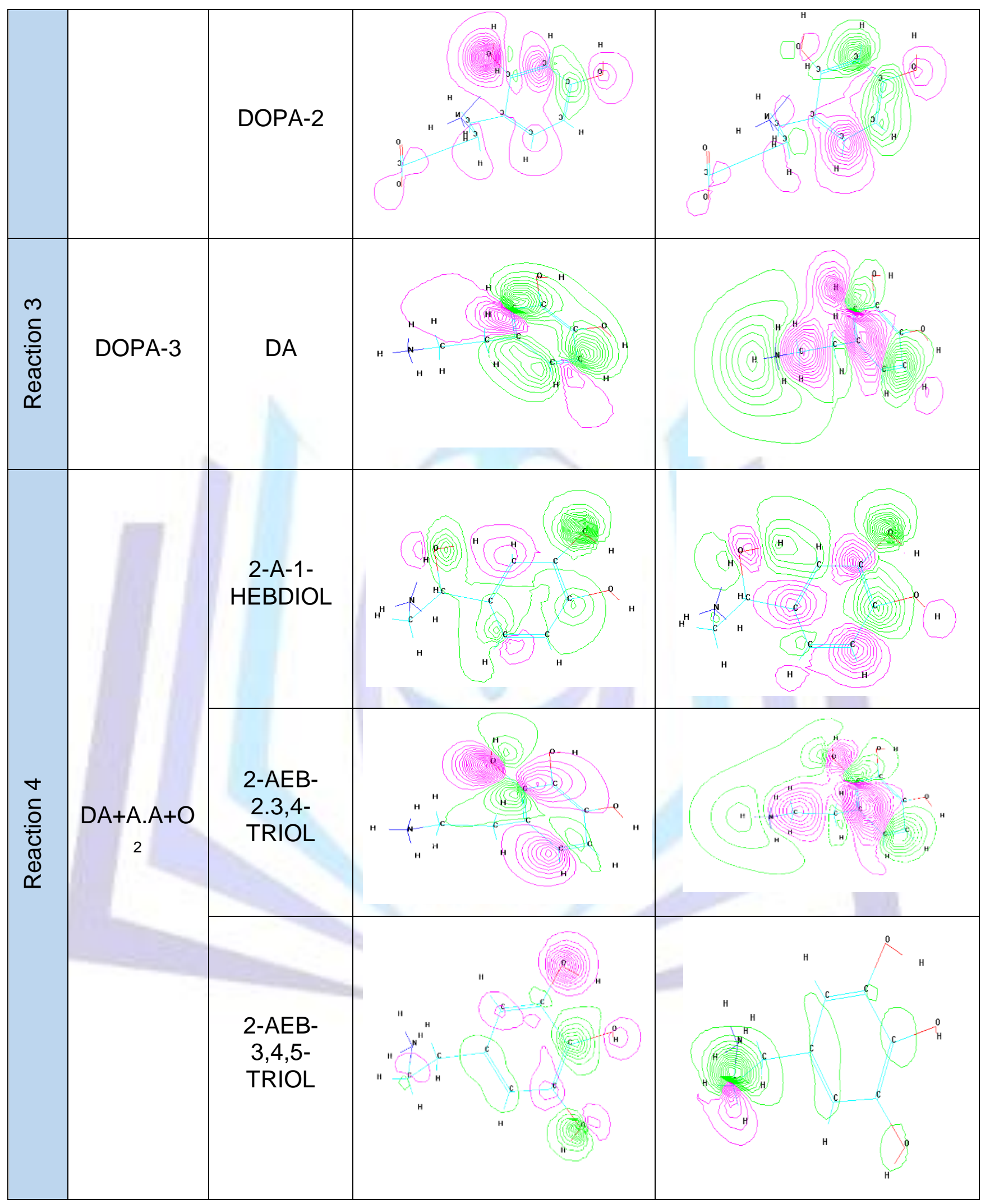


ISSN 2321-807X

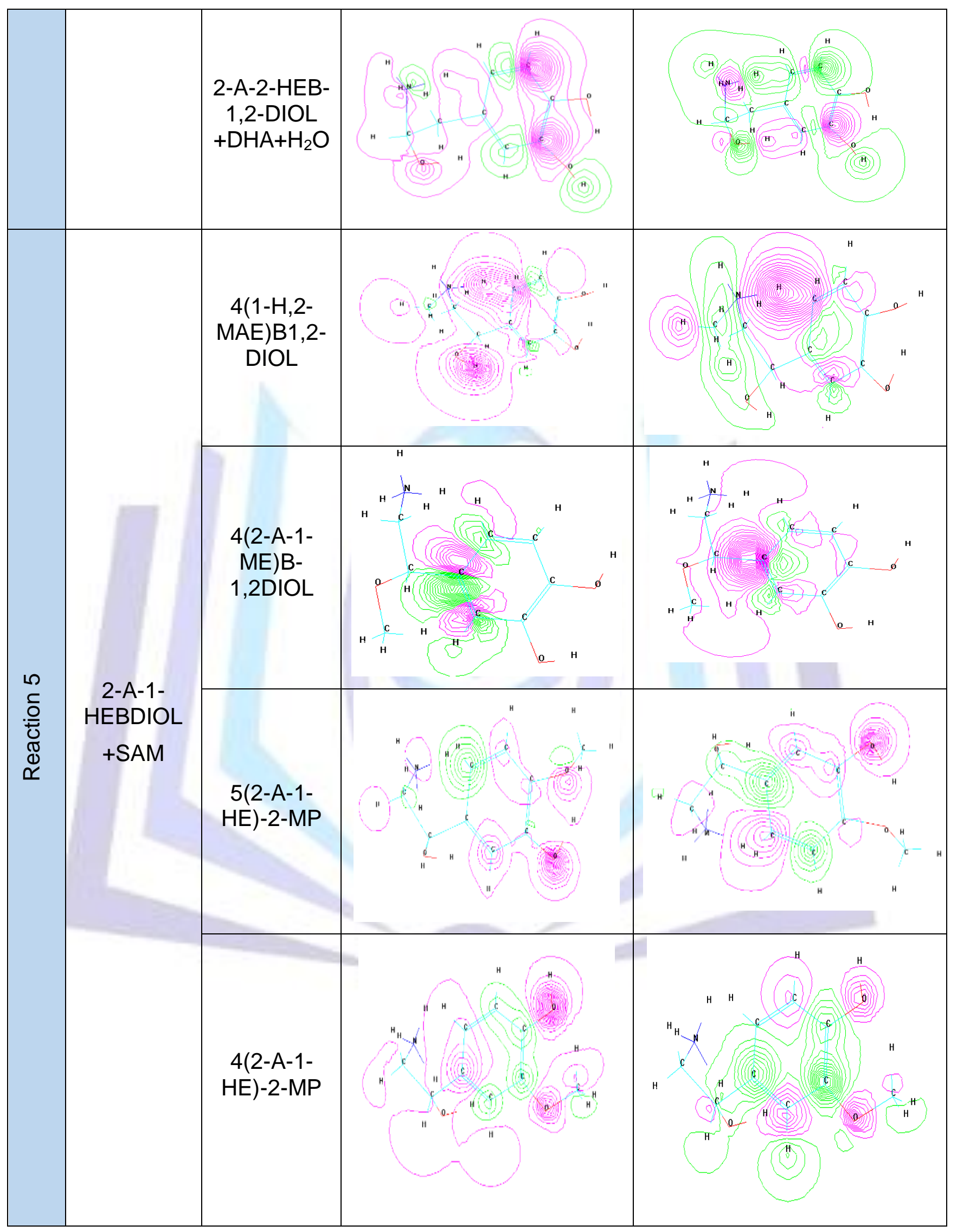




\section{CONCLUSIONS}

- The pathway of Adrenaline synthesis have been investigated accourding to theoretical calculations.

- Comparitive of chemical recations are achevied dependiong on the energetic phenomena for every stepwise reaction.

- Molecular orbital behavoure have been estimated through DFT calculation and the reactivity been determinated for all chemical mioties of chemical synthesis in vaccum.

- The reactions of synthesis are spontinously takeplaces due the biological signal transfer in brine.

\section{REFERENCES}

1. R. J. Wurtman, "Catecholamines", The New England Journal of Medicine, vol. 273, pp. 693-700, 1965.

2. T. C. Westfall, DP. Westfall, "Adrenergic agonists and antagonists In: Goodman \&Gilman's The pharmacological basis of therapeutics", New York: McGraw-Hill, pp. 215-264, 2006.

3. J.K. Aronson, "Where name and image meet: The argument for adrenaline", British Medical Journal, vol. 320, pp. 506-9, 2000.

4. T. Yamashima, "Jokichi Takamine (1854-1922), the samurai chemist, and his work on adrenalin", J Med Biogr, vol. 11, no. 2, pp. 95-102, 2003.

5. J. AXELROD, "Purification and Properties of Phenylethanolamine-N-methyl Transferase", THE JOURNAL OP BIOLOGICAL CHEMISTRY, vol. 237, no. 5, 1962.

6. I. Sheikhshoaie and S. Saeednia, "Synthesis, Characterization and Nonliner Optical Properties of Four Novel Schiff Base Compounds", The Arabian Journal for Science and Engineering, Vol. 35, pp. 53-60, 2010.

7. Abbas A-Ali Drea, Salah A-Naman and Bhajat R-Jaffer, "Theoretical Degradation Study of Methomyl", Journal of Applicable Chemistry, vol. 1, no. 1, pp. 125-136, 2012.

8. H. Adnan, S. A. Aowda and A. A-Ali Drea, "Simulation Study of alkylation reaction of resorcinol", Journal of Applicable Chemistryvol,vol. 3, no. 6, pp. 2365-2371, 2014.

9. Abbas A- Ali Drea and N. Izet, "Estimation Study of Mechanism and Kinetic for the Reactions of Ethane in Vacuum Using DFT", Journal of photocatalysis science, no. 2, vol. 3, pp. 49-59, 2012.

10. M. H. Obies, Abbas A-Ali Drea and Falah H-Hussein, "Simulation Study of Photocatalytic Decolorization of Bismarck Brown -R Using Different Quantum Calculation Methods", Int. J. Chem. Sci, vol. 10, no. 1,pp. 63-79, 2012,

11. J.C. Verster, T. Roth, "Effects of central nervous system drugs on driving: speed variability versus standard deviation of lateral position as outcome measure of the on-the-road driving test", PNAS, vol. 29, no. 1, pp. 19-24, 2014.

12. D.A.H. Cunninghama, W. Vogel and M. Haruta, "Negative activation energies in CO oxidation over an icosahedral $\mathrm{Au} / \mathrm{Mg}(\mathrm{OH}) 2$ catalyst", Catalysis Letters, vol. 63, pp. 43-47, 1990.

13. Alaa A-Hussein, and Abbas A-Ali Drea, "Theoretical investigation study of Bromine radical reaction with ozone in stratospheric layer", Journal of Applicable Chemistry, vol. 1, no. 3, pp. 453-459,2012.

14. D. Muayad, S. A. Aowda and A. A-Ali Drea, "Simulation Study of Oxidation for Oleic acid by KMnO4 Using Theoretical Calculations", Journal of Applicable Chemistry, vol. 2, no. 1, pp. 42-49, 2013.

15. Abbas A-Ali Drea, S. N. Naman and B. R. Jaffer, "Theoretical Degradation Study of Methomyl", Iraqi National Journal of Chemistry, vol. 1, no. 1, pp. 126-137, 2011.

16. M. R. Hoffmann, S. T. Martin, W. Choi, and D. W. Bahnemannt,"Environmental Applications of Semiconductor Photocatalysis", Chem. Rev, vol. 95, pp. 69-96, 1995. 